\title{
Prediction of Future Mortality in China under the New Demographic Norm
}

\author{
Chen Cuixia \\ Central University of Finance and Economics \\ China Institute for Actuarial Science
}

\begin{abstract}
In recent years, China's population life expectancy into the rapid growth stage, this population growth caused by the rapid growth of a series of risks known as longevity risk. The increase in life expectancy concerns the future survival of individuals, as well as the profitability and solvency of commercial insurers, and most importantly, the impact on pension plans throughout the country. Therefore, it is necessary to accurately predict future mortality in China at this stage. In this paper, the Lee-Carter model least square method is used to estimate the parameters. Secondly, according to the Box-Jenkins method, the ARIMA model is used to fit the forecasting of life expectancy and life expectancy.
\end{abstract}

Keywords: Lee-Carter model; mortality; life expectancy; longevity risk

The author thanks to the support from Graduate Research Innovation Fund of Central University of Finance and Economics (Project Number:201611)

\section{INTRODUCTION}

With the development of economy and sicence technology, as well as the improvement of people's living standard, people pay more and more attention to health problems. At the same time, China's medical technology is also getting huge progress, for example, the cure rate and survival rate of major diseases have been significantly improved, which makes China's population life expectancy to enter the stage of rapid growth. According to the historical data of population mortality rate, the death rate of our country has changed greatly since 1980s. As shown in Figure 1, the trend of China's population mortality by age in 1995, in 2003 and in 2013, in which the horizontal coordinate represents the age, and the ordinate indicates the level of mortality. As can be seen from the chart, the mortality curve in 2003 was significantly below the mortality rate curve in 1995, and the mortality curve in 2013 was significantly below the mortality curve in 2003. Note that in the past more than twenty years, China's population mortality rate showed siginificant decrease. According to this trend of population, this paper uses historical mortality data to predict the mortality development level and life expectancy of the population in China in the next 20 years.

With more and more prominent aging of population, the longevity risk has become a new and increasingly serious social risk faced by governments, enterprises and individuals. Broadly speaking, longevity risk refers to the risk that the real average life expectancy of the individual or the general population is higher than the life expectancy(MacMinn, Brockett,Blake,2006; Stallard, 2006). Thus, we can define the longevity risk from two aspects: the Individual Longevity Risk that means that an 


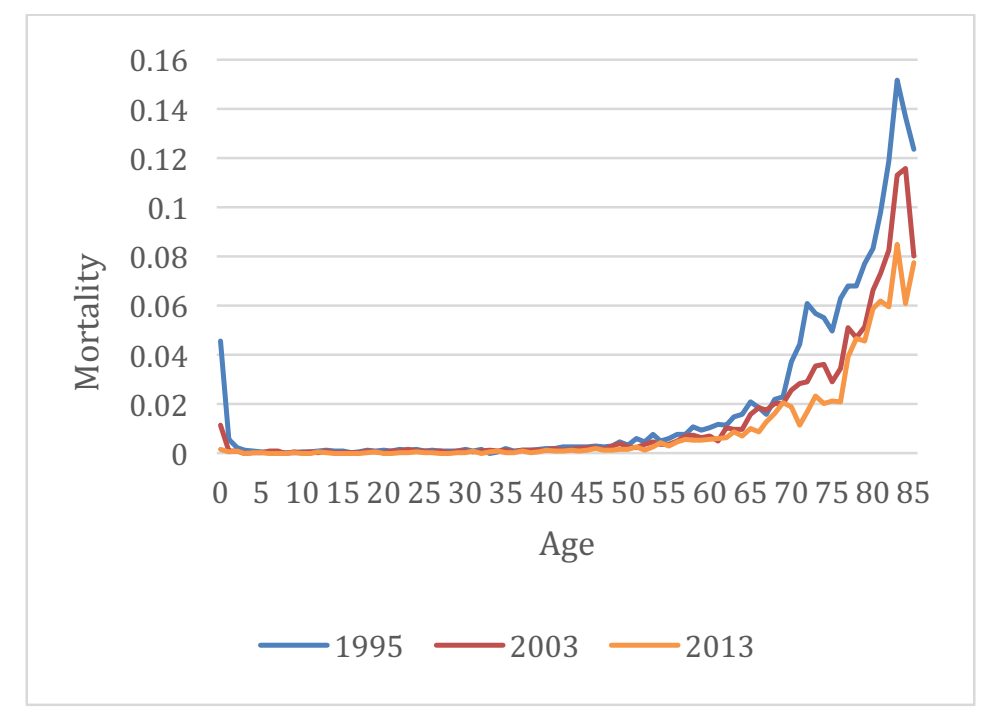

Figure 1 The trend of annual mortality rate in China

individual longevity risk from two aspects: the Individual Longevity Risk that means that a person spends more than the wealth that he has accumulated in his all life. And such risks can be managed by the pension plan, such as to buy life-insurance company, the government's social pension insurance, enterprise the endowment insurance and annuity products; the Overall Population Longevity Risk (Aggregate Longevity Risk), refers that the average survival of the population exceeds the expected period, and the risk is systematic risk that cannot be diversified according to the law of large numbers (Milevsky, Promislow, Young,2006; Cairans,Blake, Dowd, 2006a ). So life-insurance company, enterprise or government pension social insurance program, are difficult to effectively manage this aggregate longevity risk.

In conclusion, it is important to manage this longevity risk and be able to assess the severity of future longevity risk. While severity of longevity risk is evaluated by mortality, to find a reasonable mortality prediction model is very necessary. The mortality model is divided into deterministic mortality model and stochastic mortality model. Specifically, the deterministic mortality model, includes De Movire model, Gompertz model and Weillbull model and the stochastic mortality model, which is recognized as the most typical and the most widely used as a model to predict the population of the United States, is Lee-Carter model that was proposed by Lee Ronald D. and Carter Lawrence R. in the United States in 1992.

In recent years, the Lee-Carter model is used to predict population mortality are very popular among scholars all over the word. For example, Wilmoth (1996) forecasts the Japanese population mortality using the Lee-Carter model; Booth (1998) uses the Lee-Carter model for empirical data of Australia's population mortality prediction; Tuljapurkar (2000) uses the LeeCarter model to experience mortality data for Canada, France, Germany, Italy, Japan, Britain, the United States and the results are forecasting the trend decline until 2050 the mortality rate year by year linear future; Renshaw and Haberman (2003) proposes that the age changes should be added to the Lee-Carter prediction method, and carries on the forecast to 1950-1998 in England and Welsh population mortality; Haberman and Russolillo (2005) also propose that Lee-Carter model is used to predict the future mortality on the population of Italy, and in the prediction, he also carried out a complete re-estimation method for programming parameter-

; Furthermore, Delwarde (2007) estimates the death parameters using Lee-Carter model that satisfied the Poisson distribution by using the Maximum Likelihood Method; Considering 
the heterogeneity of death data, Li (2012) proposed that using two negative binomial can better simulate death data in parameter estimation in Lee-Carter model .

The relevant research of the domestic scholar, Li Nan, Hu Huaqing (1998) applies the LeeCarter model to forecast the Chinese population mortality rates firstly, and introduces this method to all the kind of aspects; Li Zhisheng and Liu Hengjia (2010) introduced the four methods to estimate the model parameters in the Lee-Carter model, including the singular value decomposition (SVD) , least squares (OLS), the weighted least squares method (WLS) and maximum likelihood (MLE). Whatever they compared these four methods of fitting effect and prediction ability; Zhu Wei and Chen Bingzheng (2009) used the Lee-Carter model to predict the city population mortality in China; Han Meng and Wang Xiaojun (2010) establish a double stochastic process of Lee-Carter model in time mortality data in order to solve the problem of insufficient sample size caused by the forecast results.

In this paper, on the basis of the scholars Lee-Carter (1992), Lee (2000), Lee and Miller (2000), Lee and Miller (2001) and Renshawand and Haberman (2003a) forecasting mortality method, using the observation of historical Chinese data (1995-2013) mortality by age and gender, we make use of Lee-Carter model to predict the future twenty years population mortality (20142033) in China, and fit the data to verify the validity and the accuracy of the prediction results of the mortality.

\section{LEE-CARTER MODEL}

In the model of stochastic mortality, Lee-Carter model is regarded as the most typical mortality prediction method, which is proposed by American scientist Lee Ronald and Carter D.in 1992 .

\section{Basic Form}

Lee and Carter (1992) decomposed the influence factors of each year, the mortality rate for age logarithm center to the time factor and the age factor, which is a logarithmic expression model and ARIMA (autoregressive integrated moving average model) extrapolation model. The basic form of Lee-Carter model is:

$$
\ln \left(m_{x, t}\right)={ }_{x}+{ }_{x}{ }_{t}+{ }_{x, t}
$$

where, $m_{x, t}$ is the center death rates for people aged $x$ in the time of $t ;{ }_{x}$ is the age factors affecting mortality that the mortality varies with age; ${ }_{x}$ is the age factor that means the sensitivity of age $x$ to the change of mortality; ${ }_{t}$ is the time factor affecting mortality that means the degree of change in mortality with time; ${ }_{x, t}$ means the residual term and satisfies

$$
{ }_{x, t} \sim N(0,2) .
$$

According to Lee-Carter (1992), the model has the property of parameterization. This reason is that the structure of the original parameter model is invariable for any constant $c$. For example, $\left\{{ }_{x},{ }_{x},{ }_{t}\right\} \quad\left\{{ }_{x},{ }_{x} / c, c_{t}\right\},\left\{{ }_{x},{ }_{x},{ }_{t}\right\} \quad\left\{{ }_{x},{ }_{x} c,_{t}+c\right\}$, where ${ }_{t}$ is determined by a linear transformation, ${ }_{x}$ is determined by a constant multiplication coefficient, and ${ }_{x}$ is determined by a linear adjustment. Therefore, in order to obtain the unique best parameter values, the following conditions must be met: $\quad{ }_{t}=0, \quad{ }_{x}=1$. 
This model, which combined the basic demographic model and statistical time series method, according to the change of long-term mortality in history and forecast the future trend of development, is simple form, weak assumptions, and effective actual prediction. Therefore, the Lee-Carter model has been regarded as the most typical random prediction method, and is widely used in many countries or regions of the projected mortality.

\section{Data}

According to "the China Population Statistical Yearbook" and "the China Population and Employment Statistics Yearbook"1, we can get a median age of 1995-2013 years of age at the center of the mortality rate in actuarial terms, which is the average number of deaths divided by the average number of years. Taking into account the differences in mortality rates between male and female in the course of prediction, we classified mortality rates by gender and predicted mortality rates for male and female separately. The data collected are processed as follows:

a. The difference between this method in this paper and the Lee-Carter model (1992) is that this article mainly estimates the each age point of mortality, which is conducive to the accurate prediction of mortality, and is conducive to the insurance companies and pension funds effectively plan their pension plans and pension products, also conducive to accurate the pricing of insurance products.

b. We can get the 0-85 years age of complete mortality data from the "China Population Statistics Yearbook" and "China population and Employment Statistics Yearbook". While the number of deaths that are more than 85 years of age is missing, so when we are dealing with the mortality data of the elderly population over 85 years old, we use the Coale-Kisker (C-K) method mentioned in Lee-Carter (1992).

c. We set the calendar year interval of 1995-2013 years (the data in 2000 and in 2010 is missing). In order to complete time series data, we passed after two years of arithmetic mean value to obtained in 2000 and 2010 data, taking into account the 1999, 2000, 2001, 2009, 2010 and 2011 did not happen during special events, so the mortality rate is not very high, therefore, we can use the closed two years of data to make relatively accurate arithmetic mean.

\section{Parameter Estimation}

The method for estimating the parameters of Lee-Carter model, Lee and Carter (1992) use the singular value decomposition (SVD) to estimate the model parameters; Haberman and Russolillo (2005) use the ordinary least squares (OLS) in the Lee-Carter model to predict mortality of Italy population. Although the ordinary least square method is used the logarithmic of mortality to solve the model, it does not need to exchange the parameter ${ }_{t}$ and ${ }_{x}$, because the ${ }_{t}$ and ${ }_{x}$ were estimated through two steps, that is to say, the second step can effectively adjust the deviation of the first step from the fitting using least square method to estimate. Therefore, on the basis of previous studies, this paper uses the ordinary least squares method (OLS) to estimate the parameters of Lee-Carter model. The method mainly has the following three steps:

\footnotetext{
1According to the "China Population Statistical Yearbook" and "Chinese population and Employment Statistics Yearbook", we can obtain the data of 1995-2013 mortality in different age and gender, and determine the mortality in each age 0-85 years old, and 85 years of age or older mortality were recorded as the overall death rate.
} 
Step 1: Estimate ${ }_{x} \cdot{ }^{\wedge}{ }_{x}={ }_{1}^{n} \ln \left(m_{x, t}\right) / n$ ( $n$ is the number of years included in the observed mortality rate, in this paper, $n=19$ ), which means that the average annual mortality rate of the population aged $x$ is calculated by the logarithm of time;

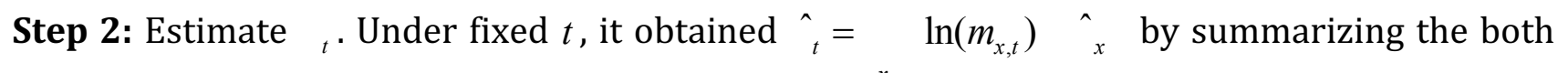
sides of the Lee-carter model equation about the age $x\left({ }_{t}=0, \quad{ }_{x}=1\right)$;

Step 3: Estimate ${ }_{x}$. It established the regression equation $\ln \left(m_{x, t}\right) \hat{x}_{x}=\hat{x}_{t}+{ }_{x, t}$, in which the variable $\ln \left(m_{x, t}\right) \quad{ }_{x}$ is the independent variable, and ${ }^{\wedge}{ }_{t}$ is interpreted as explanatory variable. The regression coefficient ${ }_{x}$ of the regression equation can be estimated by linear regression. We make use of the ordinary least squares (OLS) estimation to determine ${ }_{x}$ value

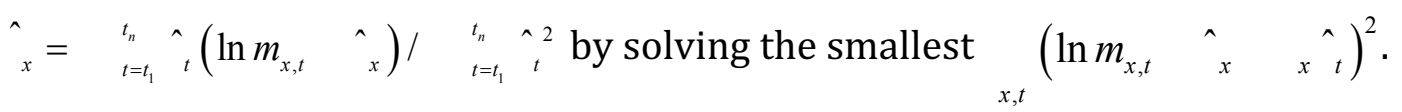

Specifically, the estimated results are as follows:

1. ${ }_{x}$. Based on the first step, the estimated values of the male and female population mortality model parameters (Appendix A) are obtained, as shown in Figure 2.

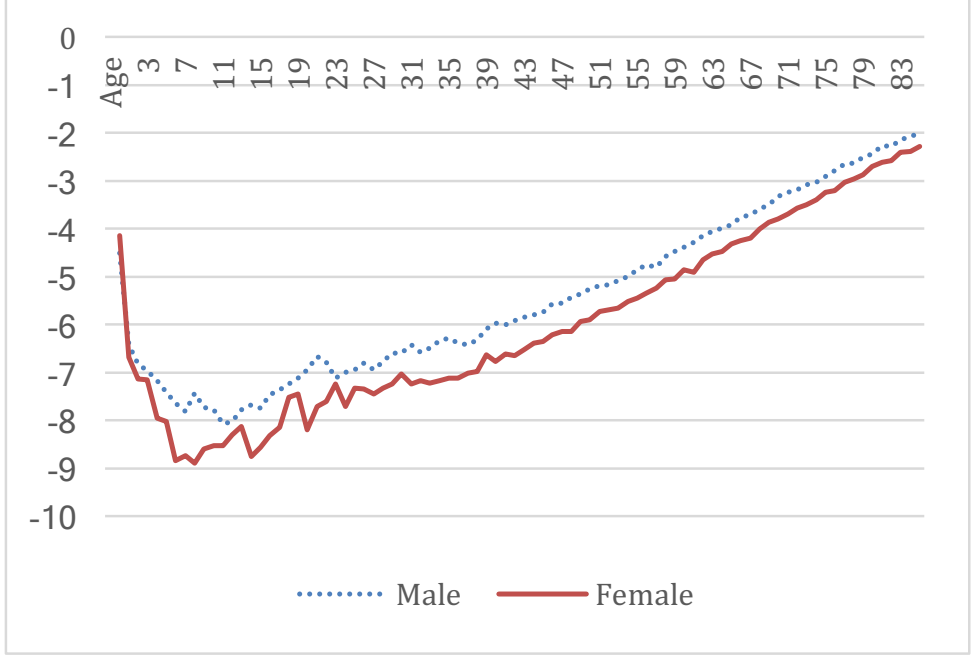

Figure 2 Parameter $x$ Estimated Values of Mortality Model by Gender

The parameter ${ }_{x}$ represents the general age pattern of the central death rate, which is the base of the time series. As can be seen from appendix A and Figure 2, the variation trends of male and female mortality model parameters are approximately the same. That is to say the higher mortality rate in the newborn period, with the increase of age, in adolescence, mortality rate is gradually decreased, but to a certain age, adulthood and old age, the mortality rate increased with the increase of age. On the other hand, it can be seen from the graph that the mortality rate of female is lower than that of male mortality, namely, the mortality rate of female population is lower than that of male at the same age.

2. ${ }_{t}$. According to the second step, the estimated values of the parameters of the mortality model of the male and female population (Appendix B) are obtained, as shown in Figure 3. 


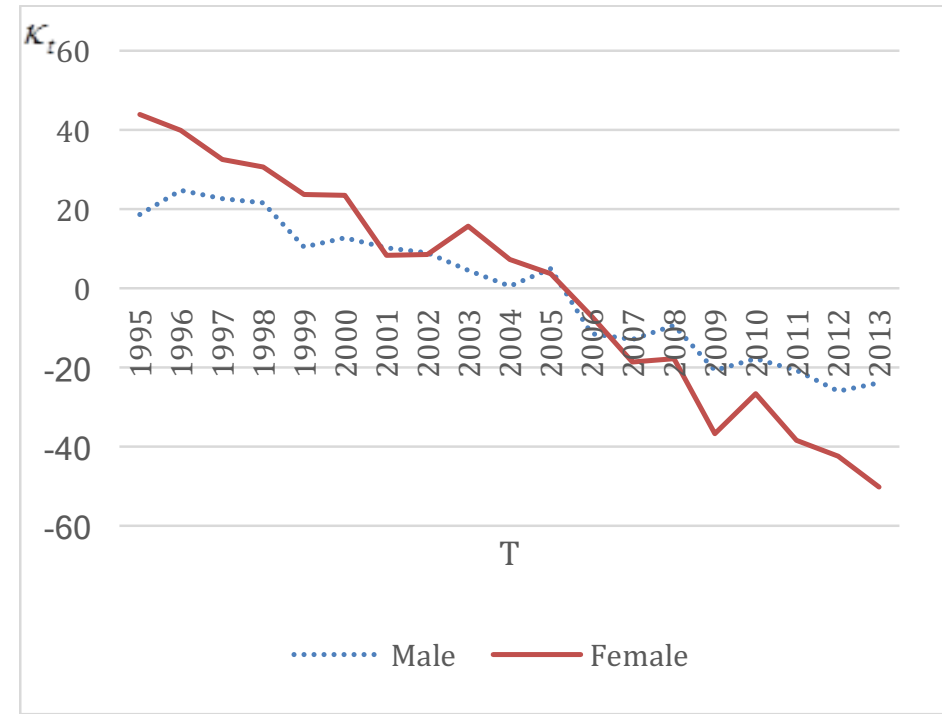

Figure 3 The Trends in the Estimated Values of Parameter ${ }^{\wedge}$ by Gender

The parameter ${ }^{\wedge}$ means the time factor of mortality. As can be seen from appendix B and figure 3 , the variation trend of the estimated parameters ${ }^{{ }}{ }_{t}$ of the male and female is approximately the same. In other words, the mortality rate is declining by time, which is consistent with the trend of mortality rate.

3. ${ }_{x}$. According to the third step, the mortality model parameter ${ }^{\wedge}$ for the male and female population (Appendix C) are obtained, as shown in Figure 4.

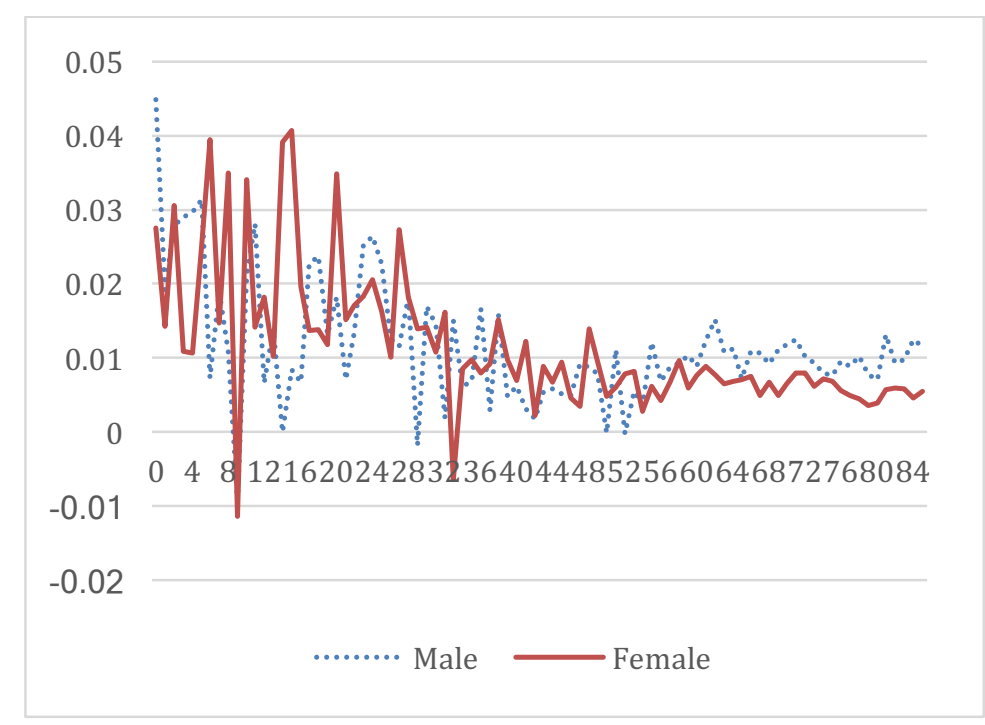

Figure 4 Parameter ${ }_{x}^{\wedge}$ Estimated Values of Mortality Model by Gender

The parameter ${ }^{\wedge}$ indicates the age factor, that is to say, age is sensitive to changes in mortality. The appendix $\mathrm{C}$ and Figure 4 shows that the parameter estimation of mortality model of male and female values in low age is relatively large, especially at birth, because the new population has a high mortality rate change on mortality; in old age, showed a downward trend, the reason is that small changes in mortality characteristics of elderly population over time, and this is not sensitive to the changes of mortality. 


\section{Re-estimation}

In the mortality parameter estimation, the first stage is the estimation of the logarithm of the mortality rate rather than the estimation of the mortality rate itself, so there is a scale deviation between the actual death toll and the predicted death toll. In order to fit the mortality distribution better, we re-estimate the parameter ${ }_{t}$ in the second stage.

According to the iterative method in Lee-Carter (1992), the estimated value ${ }_{t}$ is adjusted so that the expected total number of deaths ${ }_{x=x_{t}}^{x_{k}} e_{x, t} e^{\hat{x}+\hat{x}}$ for any $t$ is infinitely closed to the actual total number of deaths ${ }_{x=x_{t}}^{x_{k}} d_{x, t}$. The iterative process is as follows:

Step 1, For any $t$, compare ${ }_{x=x_{t}}^{x_{k}} e_{x, t} e^{\hat{x^{+} \hat{x}^{\hat{x}}}}$ to ${ }_{x=x_{t}}^{x_{k}} d_{x, t}$;

Step 2, Judgment results;

a. If ${ }_{x=x_{t}}^{x_{k}} e_{x, t} \hat{e}^{\hat{x^{+} \hat{x}^{\hat{t}}}}>{ }_{x=x_{t}}^{x_{k}} d_{x, t}$, then it need to decrease the expected numbers of deaths. Specifically, we adjust the valve of estimated $\hat{}_{t}$, if $\hat{}_{t}>0$, then make $\hat{}_{t}=\left(\begin{array}{ll}1 & d\end{array}\right)_{t}$; if $\hat{}_{t}<0$, then make $\hat{}_{t}=(1+d){ }_{t}{ }_{t}(d$ is infinitely closed to 0$)$;

b. If ${ }_{x=x_{t}}^{x_{k}} e_{x, t} e^{\hat{x^{+}} \hat{\hat{x}^{*} t}}<{ }_{x=x_{t}}^{x_{k}} d_{x, t}$, then it need to increase the expected numbers of deaths. Specifically, we adjust the valve of estimated ${ }^{{ }_{t}}$, if ${ }_{{ }_{t}}>0$, then make ${ }_{{ }_{t}}=(1+d){ }_{t}$; if $\hat{}_{t}<0$, then make $\hat{}_{t}=\left(\begin{array}{ll}1 & d\end{array}\right) \hat{}_{t}(d$ is infinitely closed to 0$)$;

c. If ${ }_{x=x_{t}}^{x_{k}} e_{x, t} e^{\hat{x}+\hat{x}^{\hat{t}}}={ }_{x=x_{t}}^{x_{k}} d_{x, t}$, then we stop the iterative process.

Step 3, Go back to the first step and compare them. It finished the iterative process until the both are very closed.

\section{THE CHOICE OF TIME SERIES MODEL}

To better estimate future mortality and life expectancy, we choose the ARIMA (p, d, q) method to model the time series. To establish the ARIMA model, we firstly determine the stationarity of the ${ }_{t}$, and then we select the best $\operatorname{ARIMA}(\mathrm{p}, \mathrm{d}, \mathrm{q})$ model to fit the historical data.

\section{ARIMA Model}

The ARIMA model named the autoregressive integrated moving average model (ARIMA), is a famous time series prediction method proposed by Box and Jenkins in the early 70s, and it is also known as the BJ model. The ARIMA (p, d, q) is called the differential autoregressive moving average model, where AR is autoregressive moving average; MA is moving average number; $d$ is the times of differential when time series become smooth; ${ }^{d} y_{t}$ denotes the time series $y_{t}$ after differential process, then the ARIMA ( $\left.p, d, q\right)$ model is formed by:

$$
{ }^{d} y_{t}=c+{ }_{1}^{d} y_{t 1}+{ }_{2}{ }^{d} y_{t 2}+\ldots+{ }_{p}^{d} y_{t p}+{ }_{t}+{ }_{1 t 1}+2 t_{t 2}+\ldots+{ }_{q t q}
$$


According to the formula (2), we should firstly determine whether the time sequence ${ }^{{ }_{t}}{ }_{i}$ is stable. If the sequence ${ }^{r}$ is unstable, we need to make the difference until the sequence ${ }^{{ }_{t}}$ is stable and $d$ is the times of differential.

The time series ${ }_{t}$ can be modeled by stochastic processes, and ARIMA (p, d, q) models suitable for mortality indices are identified by using Box and Jenkins theory methods (validationevaluation-identification). The model is modeled as follows:

1) Test stability the original sequence, if it does not meet the stationary condition, it should be transformed to a stationary sequence by differential transform or other transformations (such as the first and then the logarithmic difference);

2) Compute the ACF and PACF for stationary sequence, and to determine preliminarily the order (sum) of ARMA model $(p, q)$;

3) Estimate the parameters of the ARMA model, and then judge the significance of the parameters by statistical method, and eliminate the parameters which are not significant as far as possible;

4) Select the best model by AIC or SIC standards when there are several similar ARMA models.

\section{Test Stability ${ }^{2}$}

The Stationary Test methods can be divided into two types: one is the graph testing, which the judgment is based on the time sequence diagram and the character of the autocorrelation graph; the other is the Unit Root Test method, which is quantitative test by constructing a test statistic. In Haberman and Russolillo (2012), the first approach was used to test the stationarity of time-series models when measuring mortality in Italy using the Lee-Carter model. It is very subjective and not very accurate to judge the stationarity of time series by visual figure. In this paper the stationarity test, firstly it makes a simple judgment $p$ and $q$ value through autocorrelation and partial autocorrelation map, and then use the Unit Root Test method to test. Finally, we will make the final selection of the ARIMA model which is closer to the actual value.

Null Hypothesis: SER01 has a unit root
Exogenous: Constant
Lag Length: 2 (Automatic - based on SIC, maxlag=3)
\begin{tabular}{llll} 
& & \\
\hline \hline & t-Statistic & Prob. ${ }^{*}$ \\
\hline \hline Augmented Dickey-Fuller test statistic & -0.357403 & 0.8951 \\
\hline Test critical values: $1 \%$ level & -3.920350 & \\
& $5 \%$ level & -3.065585 & \\
& $10 \%$ level & -2.673459 & \\
\hline \hline
\end{tabular}

Figure 5 The Unit Root Test Results of Parameter ${ }_{t}^{\wedge}$ (Male)

\footnotetext{
2This is mainly due to least squares method using Lee-Carter model to estimate China's future population mortality level, we only take the male population as the sample to study, but the future mortality and life expectancy of female population will appear in the final results, the detailed process has been simplified.
} 
From the above results, the statistic $t=-0.3574$, which is more than the critical value at the $10 \%$ significance level, that is, the male sequence has the unit root and the $k_{t}$ is unstable. And then to make the first difference of the sequence ${ }{ }_{t}$, the results are as follows:

Null Hypothesis: D(SER01) has a unit root
Exogenous: Constant
\begin{tabular}{llll} 
Lag Length: 1 (Automatic - based on SIC, maxlag=3) & & \\
\hline \hline & t-Statistic & Prob.* \\
\hline \hline Augmented Dickey-Fuller test statistic & -5.592187 & 0.0004 \\
\hline Test critical values: $1 \%$ level & -3.920350 & \\
& $5 \%$ level & -3.065585 & \\
& $10 \%$ level & -2.673459 & \\
\hline \hline
\end{tabular}

\section{Figure 6 The Unit Root Test results of Parameter ${ }^{\wedge}$ (Male)}

From the above results, we can see that $t=-5.5922$, which is less than the critical value of the significance level of $1 \%$. This means that the first order difference does not exist the unit root, and it is stationary. As a result, $d=1$ can be determined in the ARIMA (p, d, q) model.

\section{Model Selection}

After the stability of the sequence is determined, the values of the autoregressive parameter $p$ and the moving average parameter $q$ are determined. In ARIMA (p, d, q) model, the identification of the lag order $p$ and $q$, the number of tools used is mainly the sample autocorrelation function (ACF) of the time series and the sample partial autocorrelation function (PACF). Based on the sample auto correlation coefficient and the partial autocorrelation coefficient, together with the related judgment, it provides a graphical reference for the choice of the model. Then we take the standard of autocorrelation definitions -- Akaike Information Criterion (AIC) and Schwarz Information Criterion (SIC), and we use these two criteria to choose an appropriate model. The following is the sample correlation function and the sample partial autocorrelation function of the time series.

Figure 7 Autocorrelation and Partial Autocorrelation Function of Sequence $\quad{ }_{t}^{\wedge}$ (Male)

\begin{tabular}{|c|c|c|c|c|c|c|c|c|}
\hline \multicolumn{2}{|c|}{ Autocorrelation } & \multicolumn{2}{|c|}{ Partial Correlation } & & $\mathrm{AC}$ & PAC & Q-Stat & Prob \\
\hline & 1 & $\square$ & 1 & 1 & -0.473 & -0.473 & 4.7417 & 0.029 \\
\hline 1 & 1 & $1 \square$ & I & 2 & -0.053 & -0.357 & 4.8059 & 0.090 \\
\hline 1 & 1 & 1 & 1 & 3 & 0.266 & 0.092 & 6.4991 & 0.090 \\
\hline $1 \square$ & 1 & 1 다 & 1 & 4 & -0.289 & -0.149 & 8.6514 & 0.070 \\
\hline 1 & 1 & 1 & 1 & 5 & 0.199 & 0.071 & 9.7436 & 0.083 \\
\hline 4 & 1 & 4 & 1 & 6 & -0.101 & -0.097 & 10.052 & 0.122 \\
\hline 1 & 1 & 1 & 1 & 7 & 0.024 & 0.055 & 10.071 & 0.185 \\
\hline 1 & 1 & I & 1 & 8 & 0.056 & -0.000 & 10.185 & 0.252 \\
\hline 1 & 1 & 1 & 1 & 9 & -0.075 & 0.042 & 10.413 & 0.318 \\
\hline 1 & 1 & 1 다 & 1 & 10 & -0.027 & -0.140 & 10.445 & 0.402 \\
\hline 4 & 1 & $1 \square$ & 1 & 11 & -0.080 & -0.220 & 10.775 & 0.462 \\
\hline 1 & 1 & 1 디 & 1 & 12 & 0.076 & -0.132 & 11.124 & 0.518 \\
\hline
\end{tabular}

According to the autocorrelation and partial autocorrelation function of the male population sequence ${ }_{t}$, the order $q$ in the autocorrelation decision MA (q), seen from Figure 7 , the 
order 1 is at the peak, followed by a rapid decline close to 0 , so the change of $q$ in the near of 1 , can be considered $q=(0,1,2)$; the order $p$ in the partial autocorrelation AR (P), seen from the figure 7 , the order 1 is also at the peak, the next order did not reach the critical value, so $p$ also changes in the vicinity of 1 , can be considered $p=(0,1,2)$. Therefore, we choose nine kind of forms (ARIMA $(0,1,0)$, ARIMA $(0,1,1)$, ARIMA $(0,1,2)$, ARIMA $(1,1,0)$, ARIMA $(1,1,1)$, ARIMA $(1,1,2)$, ARIMA $(2,1,0)$, ARIMA $(2,1,1)$, ARIMA $(2,1,2))$ to determine the appropriate ARIMA (p, 1, q) model.

Next, we use the AIC and SIC standards to determine the final ARIMA model. (as shown in Table 1).

Table 1 Comparison of ARIMA Model Fitting Effects (Male)

\begin{tabular}{|l|l|l|c|}
\hline Model & AIC & SIC & Significant \\
\hline ARIMA (0,1,0) & 6.3350 & 6.3845 & Yes \\
\hline ARIMA (0,1,1) & $\mathbf{5 . 5 9 0 1}$ & $\mathbf{5 . 6 8 9 0}$ & Yes \\
\hline ARIMA $(0,1,2)$ & 6.1260 & 6.2743 & No \\
\hline ARIMA $(1,1,0)$ & 6.2005 & 6.2985 & No \\
\hline ARIMA $(1,1,1)$ & 5.7589 & 5.9060 & No \\
\hline ARIMA (1,1,2) & 4.9107 & 5.1068 & No \\
\hline ARIMA (2,1,0) & 6.0561 & 6.2010 & No \\
\hline ARIMA $(2,1,1)$ & 5.9091 & 6.1022 & No \\
\hline ARIMA $(2,1,2)$ & 6.0497 & 6.2428 & No \\
\hline
\end{tabular}

Seen from the Table 1, according to the Minimum Information Criterion, the AIC and SIC standard values and significance of these models are compared. The model with the smallest AIC and SIC values has the optimal lag order, and the minimum information criterion can reduce the information loss of the model and improve the model fitting effect. Finally, the ARIMA $(0,1,1)$ model can be chosen to fit the variation in male mortality because it has the least loss information, and the coefficients in the model are significant.

\section{Parameter Estimation}

Next, the Eviews software is used to estimate the time series by the ordinary least squares. By ARIMA (p, d, q) model expression (2), we can see that the specific expression of ARIMA $(0,1,1)$ model is,

$$
y_{t}=c+{ }_{t}+{ }_{11}{ }_{1}
$$

According to the expression (3), the mortality index ${ }^{{ }_{t}}$ of male population is obtained. For the male population, the index ${ }_{t}$ is modeled by the ARIMA $(0,1,1)$ model, $\quad{ }_{t}=c+{ }_{t}+{ }_{1} t_{1}$; 


\begin{tabular}{lclll}
\hline \hline \multicolumn{1}{c}{ Variable } & Coefficient & Std. Error & t-Statistic & Prob. \\
\hline \hline \multicolumn{1}{c}{ C } & -3.098830 & 0.173594 & -17.85098 & 0.0000 \\
\multicolumn{1}{c}{ MA(1) } & -0.941386 & 0.033398 & -28.18655 & 0.0000 \\
\hline \hline R-squared & 0.575185 & Mean dependent var & -2.477944 \\
Adjusted R-squared & 0.548634 & S.D. dependent var & 5.593500 \\
S.E. of regression & 3.757924 & Akaike info criterion & 5.590050 \\
Sum squared resid & 225.9519 & Schwarz criterion & 5.688980 \\
Log likelihood & -48.31045 & Hannan-Quinn criter. & 5.603691 \\
F-statistic & 21.66346 & Durbin-Watson stat & 2.287774 \\
Prob(F-statistic) & 0.000264 & & & \\
\hline \hline Inverted MA Roots & .94 & & \\
\hline \hline
\end{tabular}

Figure 8 ARIMA(0,1,1) Model Regression Result (Male)

Therefore, for male population, $t_{t}=-3.0988+{ }_{t}-0.9414_{t}$, so,

$$
{ }_{t}={ }_{t 1} \quad 3.0988+{ }_{t} \quad 0.414_{t 1}
$$

\section{Model Evaluation}

This phase is model evaluation, which mainly demonstrates whether the model identification and model estimation in the previous stage are appropriate. The purpose of diagnostic tests is to determine if the model adequately fits historical data. After simulating the model in the sample of 1995-2013 years of China's population mortality data, we calculated the residual value (RESID) for each ARIMA model and obtained the following residuals.

Figure 9 Residual Curve Diagram (Male)

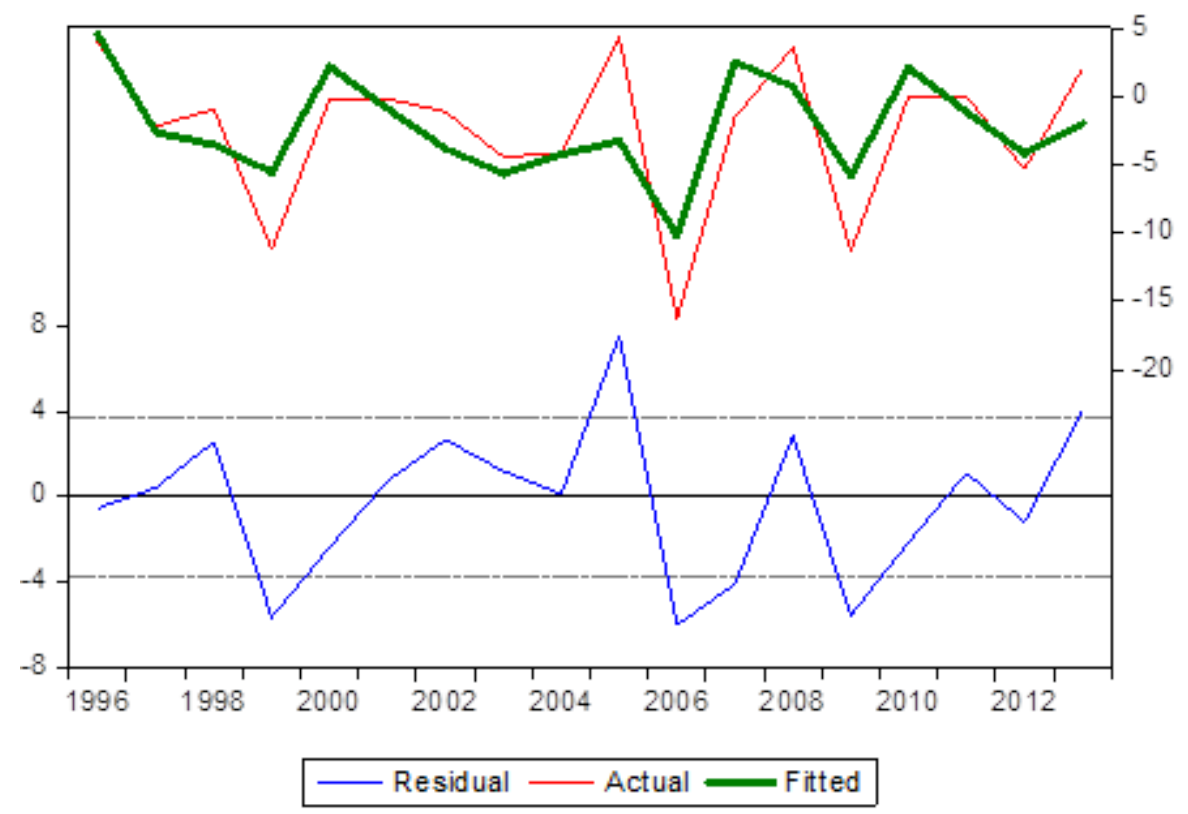

PREDICTION OF FUTURE MORTALITY AND LIFE EXPECTANCY

\section{Prediction of Future Mortality}

According to model estimation and evaluation, we now choose ARIMA $(0,1,1)$ (male) to predict the mortality index ${ }_{t}$ for the next 20 years (2014-2033), and the results are as follows: 
Table 2 Estimation of Mortality Model Parameter

\begin{tabular}{|c|c|c|c|c|c|c|c|}
\hline$t$ & $t$ & $t$ & $t$ & $t$ & $t$ & $t$ & $t$ \\
\hline 2014 & 30.82742 & 2019 & $\begin{array}{l}- \\
46.3215 \\
7\end{array}$ & 2024 & $\overline{-} 61.81572$ & 2029 & $\begin{array}{l}- \\
77.3098 \\
7\end{array}$ \\
\hline 2015 & $\begin{array}{l}- \\
33.92625\end{array}$ & 2020 & $\begin{array}{l}- \\
49.4204 \\
0\end{array}$ & 2025 & $\begin{array}{l}- \\
64.91455\end{array}$ & 2030 & $\begin{array}{l}- \\
80.4087 \\
0\end{array}$ \\
\hline 2016 & $\begin{array}{l}- \\
37.02508\end{array}$ & 2021 & $\begin{array}{l}- \\
52.5192 \\
3\end{array}$ & 2026 & $\begin{array}{l}- \\
68.01338\end{array}$ & 2031 & $\begin{array}{l}- \\
83.5075 \\
3\end{array}$ \\
\hline 2017 & $\begin{array}{l}- \\
40.12391\end{array}$ & 2022 & $\begin{array}{l}- \\
55.6180 \\
6\end{array}$ & 2027 & $\begin{array}{l}- \\
71.11221\end{array}$ & 2032 & $\begin{array}{l}- \\
86.6063 \\
6\end{array}$ \\
\hline 2018 & $\begin{array}{l}- \\
43.22274\end{array}$ & 2023 & $\begin{array}{l}- \\
58.7168 \\
9\end{array}$ & 2028 & $\begin{array}{l}- \\
74.21104\end{array}$ & 2033 & $\begin{array}{l}- \\
89.7051 \\
9\end{array}$ \\
\hline
\end{tabular}

Based on the above simulation of the time index ${ }_{t}$ of mortality, we forecast the mortality rate of male population between 2014 and 2033. According to the formula $\ln m_{x, t}={ }_{x}+{ }_{x}{ }_{t}+{ }_{x, t}$ and $\ln m_{x, t+s}={ }_{x}+{ }_{x}{ }_{t+s}+{ }_{x, t+s}$. The difference between the two formulas, therefore,

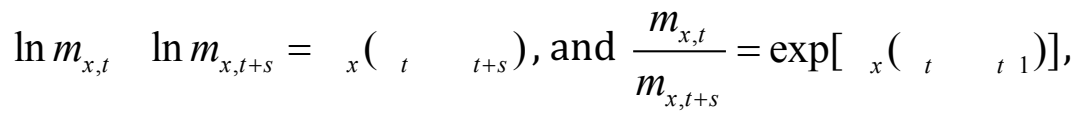

So,

$$
\left.m_{x, 2013+s}=\hat{m}_{x, 2013} \exp \left[\begin{array}{cc}
{ }_{x}\left({ }_{2013+s}\right. & \hat{2} 2013
\end{array}\right)\right], s=1,2, \ldots \ldots, 20
$$

So, the expected mortality rate $\hat{m}_{x, 2013}$ is calculated through the latest phase of historical mortality data $m_{x, 2013+s}$. Future mortality rates vary according to age, as shown in Figure 10.

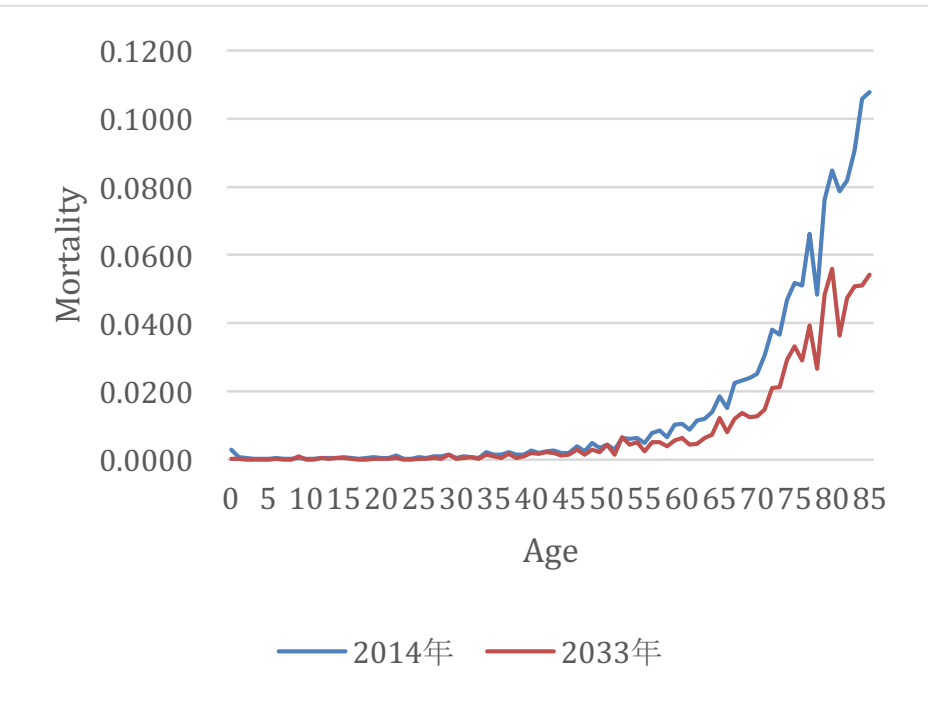

Figure 10 Annual Age-specific Mortality Prediction Chart (Male) 
As can be seen from Figure 10, the mortality curve for 2033 was significantly lower than the 2014 mortality curve for the same age, meaning that the mortality rate of the same age decreased with time. This is consistent with a trend change in pre estimated mortality rates.

\section{Prediction of Elderly Mortality}

Lee-Carter (1992) used the Coale-Kisker model (C-K) to estimate the mortality of the elderly. Coale and Kisker (1990) proposed mortality rates for elderly population to determine mortality rates over the age of 85 . The Coale-Kisker model was proposed by Ansley Coale and Ellen Kisker in 1990. The model has two basic assumptions: the increase in population mortality over 85 years of age is linearly decreasing with age; the mortality rate of a 110 year old population does not vary with time.

C-K model first defined the index $k_{x}, k_{x}=\ln \left(m_{x}\right) \ln \left(m_{x 1}\right)$, where, $m_{x}$ is the central mortality of the population aged $x$. According to the first assumption for the C-K model, $k_{x}\left(\begin{array}{ll}x & 85\end{array}\right)$ shows the liner relationship with the age $x$, that is $k_{x}=k_{85}+s\left(\begin{array}{ll}x & 85\end{array}\right)$, where $s$ denotes the change slope of the parameter $k_{x}$. So we can get the following equation:

$$
m_{x}=m_{84} \exp \left({ }_{y=85}^{x} k_{y}\right), x=85,86, \ldots
$$

Make the equation $k_{x}=k_{85}+s\left(\begin{array}{ll}x & 85\end{array}\right)$ into the equation(6), so,

$$
m_{x}=m_{84} \exp \left\{k_{y=85}^{x}\left[k_{85}+s\left(\begin{array}{ll}
x & 85
\end{array}\right)\right]\right\}, x=85,86, \ldots
$$

We let $x=105$, through equation (6), we can get the slope $s$ value,

$$
s=\ln \frac{m_{84}}{m_{105}}+21 k_{85} \quad / 210
$$

In order to reduce the effect of random fluctuation on the mortality, Coale and Kisker chosed the arithmetic average of the central mortality aged 82-86 instead of the value of $m_{84}$, with 82 to 88 years old population instead of the arithmetic mean formula $k_{85}$. That is

$$
\begin{gathered}
\hat{m}_{84}=\frac{m_{82}+m_{83}+m_{84}+m_{85}+m_{86}}{5} \\
\hat{k}_{85}=\frac{k_{82}+k_{83}+k_{84}+k_{85}+k_{86}+k_{87}+k_{88}}{7}=\ln \frac{m_{88}}{m_{81}} / 7
\end{gathered}
$$

To sum up, the original C-K model needs only 81-88 year old population center mortality data, which can be used to estimate the mortality of other elderly population. The advantages of this method are that it conforms to the characteristics of the mortality of the elderly population, and it is simple and easy to operate. The disadvantages are relatively subjective, and the central mortality rate of the final age is more arbitrary. For example, Coale and Kisker (1990) select males $m_{110}=1$, females $m_{110}=0.8$; and in our country, the life table sets the final age to 105 ; therefore, we assume that males and females $m_{105}=1$. 


\section{Life Expectancy Prediction}

The most direct way to predict population life expectancy (by age and gender)is through a random sampling of target age and target population at the same age. But the whole process of tracking a group of people is difficult to achieve in reality, and the result of this method is the historical life of many years ago. Therefore, the life table method is usually used in actual calculations, and the life table and life expectancy at birth can be derived from the mortality rate. Therefore, in actual calculations, we calculated mortality risk exposures at all ages based on mortality at various ages, and then calculated the average life expectancy of newborn infants. To sum up, (refer to appendix D related formula), from the central mortality rate from the life table method, we can figure out the life expectancy of the newborn in the next 20 years, as shown in the following figure.

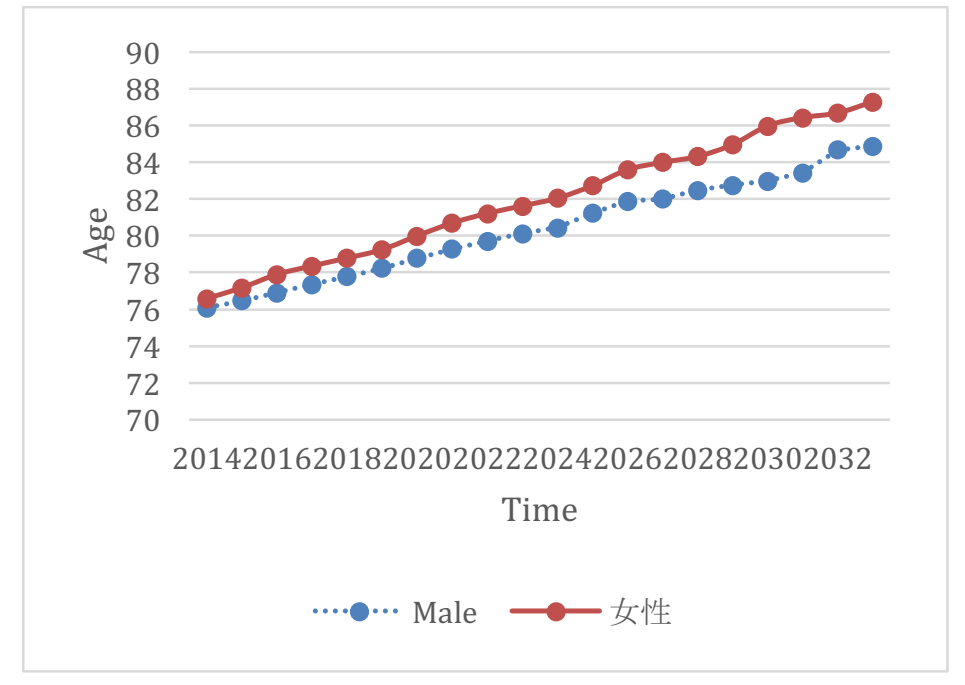

Figure 11 Prediction of Neonatal Mean Life Expectancy (by Gender)

Figure 11 shows the average life expectancy of newborns in the next 2014-2033 years, and it can be seen that the average life expectancy of the population increases significantly over time. By 2033, the average life expectancy of the male population was 85 years, and the average life expectancy of the female population reached 88 years, and there was a trend that the female population had a longer life expectancy than men.

\section{CONCLUSION}

In this paper, a method based on the Lee-Carter model is proposed to predict future mortality and future life expectancy. And based on the time series process, we choose the ARIMA model to simulate the time factor, and finally we get a set of ARIMA model which can simulate the historical data well. Finally, mortality rates and life expectancy over the next 20 years (20142033 years) are predicted based on China's 1995-2013 year mortality rate for men and women. Through detailed analysis, we can see that China's mortality rate in the next 20 years has shown a downward trend, and the average life expectancy of the population has also increased significantly over time. As the article puts forward, the existence of longevity risk brings some risks to China's Business insurance company, enterprise pension and social pension plans. Therefore, our urgent task is to draw on the domestic and foreign scholars' research and successful cases to manage the risk of longevity, effectively alleviate the pressure of aging and longevity risk, and bring pressure to society. 


\section{References}

Han Meng, Wang Xiaojun..Lee-Carter model' s application and improvement in the prediction of urban population mortality in China [J]. Insurance research, 2010 (10): 3-9.

Haberman.S., Russolillo. Lee-Carter Mortality forecasting: Application to the Italian population, Actuarial Research Paper No.167, 2005.

Lee, R., The Lee-Carter method for foresting mortality, with various extensions and applications, North American Actuarial Journal, 2000(4): 80-93.

Lee, R., and Miller, T, Evaluating the performance of the Lee-Carter method for forecasting mortality. Demography, 2001(38): 537-549.

Lee R. and Carter L. Modeling and Forecasting U.S. Mortality, Journal of the American Statistical Association, 1992(87): 659-671.

Li, J. S.-H., Hardy, M., and Tan, K. Uncertainty in Mortality Forecasting: An Extension to the Classic Lee-Carter Approach, ASTIN Bulletin, 2009(39): 137-164.

Li, N., and R. D. Lee, Coherent Mortality Forecasts for a Group of Populations: An Extension of the Lee-Carter Method, Demography, 2005 (42): 575-594.

Li, J. S.-H., Chan,W., and Cheung, S., Structural Changes in the Lee-Carter Mortality Indexes: Detection and Implications, North American Actuarial Journal, 2007(15): 13-31.

Li, J. S.-H., and Hardy, M. R., Measuring Basis Risk involved in Longevity Hedges, North American Actuarial Journal, 2001(15): 177-200.

Ming Zhou and Kam C. Yuen., "Portfolio selection by minimizing the present value of capital injection costs". Astin Bulletin, 2015 (1): 207-238.

Milevsky M. A., Promislow S. D. and Young V. R., Killing the Law of Large Numbers: Mortality Risk Premiums and the Sharpe Ratio, 2016(4):673-686.

Renshaw, A., Haberman, S., Lee-Carter mortality forecasting: a parallel generalized linear modelling approach for England and Wales mortality projections, Applied Statistics, 2003(52): 119-137.

Tuljapurkar, S., Li. N and Boe C.A. University Pattern of Mortality decline the G7 countries, nature, 2000(405): 89792.

Wang Xiaojun, Cai Zhenggao. New progress in mortality prediction model [J]. statistical research, 2008 (9): 81-84.

Zhu Wei, Chen Bingzheng. Prediction of mortality of urban population in China. [J]., mathematical statistics and management, 2009 (4):101-105. 


\section{Appendix A Parameter ${ }_{x}$ Estimated Values of Mortality Model by Gender}

\begin{tabular}{|c|c|c|c|c|c|c|c|c|}
\hline \multirow{2}{*}{$\begin{array}{l}\text { 年 } \\
\text { 龄 }\end{array}$} & \multicolumn{2}{|c|}{$\hat{\hat{x}_{x}}$} & \multirow{2}{*}{$\begin{array}{l}\text { 年 } \\
\text { 龄 }\end{array}$} & \multicolumn{2}{|c|}{ 人 } & \multirow{2}{*}{$\begin{array}{l}\text { 年 } \\
\text { 龄 }\end{array}$} & \multicolumn{2}{|c|}{$\hat{x}$} \\
\hline & 男性 & 女性 & & 男性 & 女性 & & 男性 & 女性 \\
\hline 0 & -4.5127 & -4.1490 & 29 & -6.5860 & -7.2394 & 58 & -4.5748 & -5.0617 \\
\hline 1 & -6.4174 & -6.6744 & 30 & -6.5919 & -7.0338 & 59 & -4.4669 & -5.0393 \\
\hline 2 & -6.8173 & -7.1319 & 31 & -6.4254 & -7.2402 & 60 & -4.3792 & -4.8591 \\
\hline 3 & -6.9635 & -7.1515 & 32 & -6.5815 & -7.1673 & 61 & -4.2807 & -4.9104 \\
\hline 4 & -7.1644 & -7.9512 & 33 & -6.4891 & -7.2198 & 62 & -4.1363 & -4.6393 \\
\hline 5 & -7.4166 & -8.0115 & 34 & -6.3341 & -7.1741 & 63 & -4.0534 & -4.5277 \\
\hline 6 & -7.6365 & -8.8409 & 35 & -6.2784 & -7.1144 & 64 & -3.9817 & -4.4798 \\
\hline 7 & -7.8126 & -8.7402 & 36 & -6.3821 & -7.1240 & 65 & -3.9162 & -4.3110 \\
\hline 8 & -7.4228 & -8.8930 & 37 & -6.4161 & -7.0059 & 66 & -3.7601 & -4.2473 \\
\hline 9 & -7.7298 & -8.5989 & 38 & -6.3193 & -6.9752 & 67 & -3.7048 & -4.1927 \\
\hline 10 & -7.7683 & -8.5273 & 39 & -6.0942 & -6.6251 & 68 & -3.5840 & -4.0054 \\
\hline 11 & -8.0751 & -8.5291 & 40 & -5.9637 & -6.7609 & 69 & -3.4934 & -3.8607 \\
\hline 12 & -8.0197 & -8.2922 & 41 & -6.0002 & -6.6117 & 70 & -3.3267 & -3.7870 \\
\hline 13 & -7.7732 & -8.1268 & 42 & -5.9227 & -6.6545 & 71 & -3.2386 & -3.6933 \\
\hline 14 & -7.6782 & -8.7507 & 43 & -5.8480 & -6.5220 & 72 & -3.1878 & -3.5695 \\
\hline 15 & -7.7477 & -8.5501 & 44 & -5.7994 & -6.3779 & 73 & -3.0877 & -3.4988 \\
\hline 16 & -7.4565 & -8.3098 & 45 & -5.7339 & -6.3498 & 74 & -3.0321 & -3.3938 \\
\hline 17 & -7.3597 & -8.1384 & 46 & -5.5753 & -6.2080 & 75 & -2.9082 & -3.2433 \\
\hline 18 & -7.2439 & -7.5158 & 47 & -5.5480 & -6.1454 & 76 & -2.7809 & -3.2049 \\
\hline 19 & -7.1079 & -7.4518 & 48 & -5.4341 & -6.1336 & 77 & -2.6505 & -3.0379 \\
\hline 20 & -6.9441 & -8.1938 & 49 & -5.3674 & -5.9357 & 78 & -2.6223 & -2.9579 \\
\hline 21 & -6.6707 & -7.7145 & 50 & -5.2484 & -5.8937 & 79 & -2.5146 & -2.8792 \\
\hline 22 & -6.7857 & -7.5970 & 51 & -5.1836 & -5.7305 & 80 & -2.4406 & -2.7079 \\
\hline 23 & -7.1187 & -7.2412 & 52 & -5.1639 & -5.6912 & 81 & -2.2670 & -2.6128 \\
\hline 24 & -6.9852 & -7.7131 & 53 & -5.0834 & -5.6519 & 82 & -2.2822 & -2.5773 \\
\hline 25 & -6.9416 & -7.3221 & 54 & -4.9933 & -5.5106 & 83 & -2.1400 & -2.4123 \\
\hline 26 & -6.8008 & -7.3475 & 55 & -4.8551 & -5.4396 & 84 & -2.0690 & -2.3806 \\
\hline 27 & -6.9439 & -7.4497 & 56 & -4.7510 & -5.3373 & 85 & -2.0011 & -2.2818 \\
\hline 28 & -6.7718 & -7.3202 & 57 & -4.8025 & -5.2401 & & & \\
\hline
\end{tabular}




\begin{tabular}{|c|c|c|c|c|c|}
\hline \multicolumn{6}{|c|}{ Appendix B Parameter } \\
\hline \multirow{2}{*}{ 时间 } & \multicolumn{2}{|c|}{$\hat{t}$} & \multirow{2}{*}{ 时间 } & \\
\hline & 男性 & 女性 & & 男性 & 女性 \\
\hline 1995 & 18.70789 & 43.86599 & 2005 & 4.876376 & 3.707157 \\
\hline 1996 & 24.72022 & 39.87073 & 2006 & $\begin{array}{c}- \\
11.353413\end{array}$ & -6.990274 \\
\hline 1997 & 22.55712 & 32.46690 & 2007 & $\begin{array}{c}- \\
12.883445\end{array}$ & $\begin{array}{c}- \\
18.558022\end{array}$ \\
\hline 1998 & 21.62128 & 30.70863 & 2008 & -9.281936 & $\begin{array}{c}- \\
17.761577 \\
\end{array}$ \\
\hline 1999 & 10.45232 & 23.69084 & 2009 & $\begin{array}{c}- \\
20.613211\end{array}$ & $\begin{array}{c}- \\
36.717756\end{array}$ \\
\hline 2000 & 12.85635 & 23.49191 & 2010 & $\begin{array}{c}- \\
17.676969\end{array}$ & $\begin{array}{c}- \\
26.599007\end{array}$ \\
\hline 2001 & 10.17263 & 8.33133 & 2011 & $\begin{array}{c}- \\
20.593033\end{array}$ & $\begin{array}{c}- \\
38.390087\end{array}$ \\
\hline 2002 & 9.06531 & 8.53460 & 2012 & $\begin{array}{c}- \\
25.917476\end{array}$ & 42.304687 \\
\hline 2003 & 4.64110 & 15.65006 & 2013 & $\begin{array}{c}- \\
23.893153 \\
\end{array}$ & $\begin{array}{c}- \\
50.264185 \\
\end{array}$ \\
\hline 2004 & 0.54006 & 7.26746 & & & \\
\hline
\end{tabular}


Appendix C Parameter ${ }_{x}^{\wedge}$ Estimated Values of Mortality Model by Gender

\begin{tabular}{|c|c|c|c|c|c|c|c|c|}
\hline \multirow{2}{*}{$\begin{array}{l}\text { 年 } \\
\text { 龄 }\end{array}$} & \multicolumn{2}{|c|}{$\hat{x}$} & \multirow{2}{*}{$\begin{array}{l}\text { 年 } \\
\text { 龄 }\end{array}$} & \multicolumn{2}{|c|}{$\hat{x}$} & \multirow{2}{*}{$\begin{array}{l}\text { 年 } \\
\text { 龄 }\end{array}$} & \multicolumn{2}{|c|}{$x$} \\
\hline & 男性 & 女性 & & 男性 & 女性 & & 男性 & 女性 \\
\hline 0 & 0.00481 & 0.0275 & 29 & 0.00002 & 0.0139 & 58 & 0.00031 & 0.0096 \\
\hline 1 & 0.00335 & 0.0143 & 30 & 0.00496 & 0.0141 & 59 & -0.00045 & 0.0059 \\
\hline 2 & 0.00418 & 0.0306 & 31 & 0.00226 & 0.0108 & 60 & 0.00168 & 0.0076 \\
\hline 3 & 0.00843 & 0.0109 & 32 & 0.00262 & 0.0162 & 61 & 0.00017 & 0.0089 \\
\hline 4 & 0.00480 & 0.0106 & 33 & 0.00542 & -0.0064 & 62 & 0.00050 & 0.0077 \\
\hline 5 & 0.00337 & 0.0252 & 34 & -0.00122 & 0.0085 & 63 & 0.00164 & 0.0065 \\
\hline 6 & 0.00041 & 0.0395 & 35 & 0.00089 & 0.0098 & 64 & 0.00110 & 0.0068 \\
\hline 7 & 0.00139 & 0.0147 & 36 & 0.00001 & 0.0080 & 65 & 0.00140 & 0.0071 \\
\hline 8 & 0.00633 & 0.0350 & 37 & -0.00124 & 0.0092 & 66 & 0.00096 & 0.0075 \\
\hline 9 & -0.00059 & -0.0114 & 38 & 0.00074 & 0.0151 & 67 & 0.00009 & 0.0049 \\
\hline 10 & 0.00119 & 0.0341 & 39 & 0.00210 & 0.0098 & 68 & 0.00161 & 0.0067 \\
\hline 11 & 0.00303 & 0.0141 & 40 & -0.00055 & 0.0069 & 69 & 0.00007 & 0.0049 \\
\hline 12 & -0.00288 & 0.0182 & 41 & 0.00099 & 0.0122 & 70 & 0.00052 & 0.0065 \\
\hline 13 & -0.00054 & 0.0102 & 42 & 0.00020 & 0.0022 & 71 & 0.00075 & 0.0080 \\
\hline 14 & 0.00015 & 0.0391 & 43 & 0.00008 & 0.0088 & 72 & 0.00127 & 0.0080 \\
\hline 15 & -0.00295 & 0.0407 & 44 & 0.00209 & 0.0067 & 73 & 0.00076 & 0.0061 \\
\hline 16 & 0.00192 & 0.0197 & 45 & 0.00202 & 0.0094 & 74 & 0.00005 & 0.0072 \\
\hline 17 & 0.00209 & 0.0137 & 46 & -0.00024 & 0.0046 & 75 & 0.00072 & 0.0068 \\
\hline 18 & 0.00219 & 0.0138 & 47 & 0.00206 & 0.0034 & 76 & -0.00011 & 0.0056 \\
\hline 19 & 0.00013 & 0.0118 & 48 & -0.00086 & 0.0139 & 77 & 0.00000 & 0.0049 \\
\hline 20 & 0.00351 & 0.0348 & 49 & 0.00123 & 0.0095 & 78 & 0.00060 & 0.0045 \\
\hline 21 & 0.00385 & 0.0151 & 50 & 0.00077 & 0.0048 & 79 & 0.00002 & 0.0036 \\
\hline 22 & -0.00032 & 0.0171 & 51 & 0.00267 & 0.0060 & 80 & 0.00154 & 0.0039 \\
\hline 23 & 0.00308 & 0.0183 & 52 & -0.00051 & 0.0078 & 81 & 0.00004 & 0.0057 \\
\hline 24 & 0.00734 & 0.0205 & 53 & -0.00014 & 0.0082 & 82 & -0.00009 & 0.0059 \\
\hline 25 & 0.00050 & 0.0163 & 54 & 0.00026 & 0.0028 & 83 & 0.00085 & 0.0058 \\
\hline 26 & 0.00367 & 0.0101 & 55 & 0.00186 & 0.0062 & 84 & 0.00072 & 0.0046 \\
\hline 27 & -0.00073 & 0.0273 & 56 & 0.00002 & 0.0042 & 85 & 0.00090 & 0.0055 \\
\hline 28 & 0.00024 & 0.0182 & 57 & 0.00496 & 0.0067 & & & \\
\hline
\end{tabular}

Appendix D China life insurance experience life table (2000-2003) non-pension business (male) example is as following.

\begin{tabular}{|c|c|c|c|c|c|c|}
\hline Age & $\begin{array}{c}\text { Mortali } \\
\text { ty }\end{array}$ & Survival & Deaths & $\begin{array}{c}\text { Average Life } \\
\text { Time }\end{array}$ & \multicolumn{2}{|c|}{$\begin{array}{c}\text { Years of } \\
\text { Survival }\end{array}$} \\
\hline$x$ & $q_{x}$ & $l_{x}$ & $d_{x}$ & $e$ & $L_{x}$ & $T_{x}$ \\
\hline 0 & $\begin{array}{c}0.0007 \\
22\end{array}$ & 1000000 & 722 & 76.7 & $\begin{array}{c}9996 \\
39\end{array}$ & $\begin{array}{c}76712 \\
704\end{array}$ \\
\hline
\end{tabular}

The specific formulas and related expressions are as following:

(1) ${ }_{t} d_{x}$ : The deaths of the population aged $x$ at the interval time $(x, x+n]$, so ${ }_{t} d_{x}=l_{x} l_{x+t}$; 
(2) ${ }_{t} q_{x}$ : The years of the survival population aged $x$ at the interval time $(x, x+n]$, so ${ }_{t} q_{x}=\frac{{ }_{t} d_{x}}{l_{x}}$;

(3) ${ }_{t} L_{x}$ : The deaths of the population aged $x$ at the interval time $(x, x+n]$, so ${ }_{t} L_{x}={ }_{x}^{x+n} l_{t} d t$;

${ }_{t} L_{x}$ denotes the total survival time of all surviving individuals exposed to the risk of death during this period, also known as the "exposure number", which is a unit of total survival time. It is assumed that the time of death is evenly distributed in the integer age range, so the deaths $d_{x}$ at the $(x, x+1]$, average survival the half of year, so,

$$
L_{x} \quad 1 \cdot l_{x+1}+\frac{1}{2} d_{x}=l_{x+1}+\frac{1}{2}\left(l_{x} l_{x+1}\right)=\frac{1}{2}\left(l_{x}+l_{x+1}\right)
$$

(4) $T_{x}$ : The cumulative number of years old $x$ people survive in the future, so $T_{x}=L_{n}$;

(5) $e_{x}$ : The average residual life of an elderly population aged $x$, so $e_{x}=T_{x} / l_{x}$;

(6) ${ }_{t} m_{x}$ : In demography, there is a more commonly used concept of mortality, that is, central mortality, which refers to the conditional measure of mortality in the age range $(x, x+n]$. It is defined as the weighted average of the hazard function on the unit interval, and the weight is the survival function. So, the relationship ${ }_{n} m_{x}$ and ${ }_{n} q_{x}$ is: ${ }_{n} m_{x}=\frac{{ }_{n} q_{x}}{n n_{n}\left(1_{n} f_{x}\right)_{n} q_{x}}$.

When compiling life tables from demographic data, central mortality rates are easier to obtain because of the limited data, assuming that the time of death is evenly distributed within the integer interval $(x, x+n]$. So ${ }_{n} f_{x}=1 / 2$, there is ${ }_{n} q_{x}=\frac{{ }_{n} m_{x}}{1 / n+{ }_{n} m_{x} / 2}$.

In conclusion, the central mortality $m_{x, t}=\frac{d_{x, t}}{L_{x, t}}=\frac{d_{x, t}}{\frac{1}{2}\left(l_{x}+l_{x+1}\right)}=\frac{d_{x, t}}{e_{x, t}}$, where $d_{x, t}$ refers to the total number of deaths of the year old $x$ in the year $t$, that is, $d_{x, t}=l_{x} l_{x+t} ; e_{x, t}$ is the average number of people surviving at the age of $x$, that is, $e_{x, t}=\frac{l_{x+t}+l_{x}}{2}$. 